\title{
The impact of the use of bioresorbable vascular scaffolds and drug-coated balloons in coronary bifurcation lesions
}

\author{
Mostafa Elwany ${ }^{1,2^{*}}$ (D), Amr Zaki ${ }^{2}$, Azeem Latib ${ }^{3}$, Luca Testa ${ }^{4}$, Alfonso lelasi ${ }^{5}$, Davide Piraino ${ }^{6}$, Salvatore Geraci ${ }^{7}$, \\ Tarek El Zawawy ${ }^{2}$ and Bernardo Cortese $e^{1,8}$
}

\begin{abstract}
Background: Despite the improvement in techniques and tools, coronary lesions involving a bifurcation are still challenging and the outcome with drug-eluting stents is not always optimal. The role of bioresorbable vascular scaffolds (BVS) and drug-coated balloons (DCB) in this setting has not been adequately investigated yet.

Results: From the databases of 6 italian centers with high proficiencies in newer technologies, we retrospectively collected all consecutive cases of coronary bifurcations managed or attempted with the implantation of at least one BVS in the main vessel and the use of one DCB in the side branch (SB). Primary study endpoint was the occurrence of major adverse cardiovascular events (MACE) at the longest available follow-up. Fourty patients fulfilled the enrollment criterion, $22.5 \%$ had diabetes and $50 \%$ an acute coronary syndrome. Average syntax score was $15.04 \pm 7.18$, all lesions were de novo, and 27 patients (67.5\%) had a type 1,1,1 Medina lesion. Twenty-three lesions (57.5\%) involved the proximal left anterior-descending artery/first diagonal branch. Only $32.5 \%$ of patients underwent an intravascular imaging-guided angioplasty. Average lesion length was $21.4 \mathrm{~mm}$ in the main vessel and $11.49 \mathrm{~mm}$ in the SB. MV was always predilated and BVS received a postdilation in $100 \%$ of the cases. In $42.5 \%$ of the cases, the DCB was used during final kissing balloon inflation, and in no cases, a stent/BVS was required in the SB. Procedural success was achieved in 100\% of the cases. After an average follow-up of 15.5 ( \pm 11.5$)$ months, we observed no MACE with only one case of target vessel revasularization (2.5\%).
\end{abstract}

Conclusions: Management of coronary bifurcation lesions with the use of newer technologies including BVS and DCB seems feasible and effective at mid-term and long-term clinical follow-up.

Keywords: Bioresorbable vascular scaffolds (BVS), Drug-coated balloons (DCB), Coronary bifurcation lesions

\section{Background}

Despite the advances in the field of interventional cardiology, coronary bifurcations lesions, which represent approximately $15-25 \%$ of percutaneous coronary interventions (PCI) cases, are still a challenge [4].

Bioresorbable vascular scaffolds (BVS), which dissolve after fulfilling their support function have been a perennial aim and their introduction to the field of interventional cardiology represented a revolution and hope for vascular reparative therapy [8].

\footnotetext{
* Correspondence: mostafaelwany@gmail.com

'Interventional Cardiology, San Carlo Clinic, Milano, Italy

${ }^{2}$ Faculty of Medicine, University of Alexandria, Alexandria, Egypt

Full list of author information is available at the end of the article
}

The Absorb BVS (Abbott Vascular, Santa Clara, CA, USA) is a fully bioresorbable scaffold where the resorption process progresses gradually, mainly secondary to hydrolysis creating minimal or no inflammation. One of the major limitations of the BVS is the 157 microns strut thickness [14] which make it bulky .

It is reasonable to expect that the theoretical advantages of BVS over metallic drug eluting stents (DES) are to be more pronounced in the subset of coronary bifurcation lesions. Several reasons make us believe in this conclusion; first, arterial healing is faster with the BVS than DES especially if a 2 stent technique was used. Second, late luminal enlargement is secondary to BVS 
degradation. Third, jailing of the SB is no longer permanent thanks to the resorption of the BVS [15].

Provisional approach remains the gold standard for percutaneous treatment of patients with unselected bifurcated lesions even when the use of BVS is intended [1].

Side branch (SB) management is still a challenge. The use drug-coated balloon (DCB) for addressing such an issue may prove advantageous as compared to regular balloon angioplasty [10].

Our aim in this study was to evaluate the performance of BVS and DCB in bifurcation lesions at midterm follow-up in order to gain a better understanding of their efficacy and safety at this clinical setting.

\section{Methods}

The study is a retrospective study where patients were enrolled from 6 Italian centers over the period from July 2013 to July 2017 with at least 6 months follow-up after the index procedure of the last patient to the maximum available follow-up. The study included all consecutive cases of coronary bifurcations managed or attempted with:

(a) The implantation of at least one Absorb BVS in the main vessel.

(b) The use of one or more DCB in the side branch.

\section{Exclusion criteria}

1. Cardiogenic shock

2. Severe renal impairment (creatinine clearance $<30$ $\mathrm{ml} / \mathrm{min}$ ) or dependence on dialysis.

3. Contraindication to prolonged dual antiplatelet therapy.

Clinical data, including age, sex, risk factors (hypertension, diabetes, dyslipidemia, smoking and family history) and history (previous MI, previous PCI, previous bypass surgery, cerebrovascular disease CABG) was thoroughly obtained. The clinical indication (chronic stable angina, unstable angina, STEMI, or NSTEMI) was also included in the study. Renal function was withdrawn and transthoracic echocardiography was performed in all patients.

The PCI procedural details were also recorded including type of bifurcation lesion (according to Medina classification) [12], Syntax score, intravascular imaging, balloon predilation, BVS, and DCB used and balloon postdilatation.

Follow-up at the maximum available timing with a minimum of 6 months was done for major adverse cardiovascular events including death, non-fatal MI, scaffold thrombosis, and cerebrovascular stroke.

\section{Results}

Forty patients fulfilled the enrollment criteria, $22.5 \%$ had diabetes and $50 \%$ an acute coronary syndrome at presentation. The demographic and clinical characteristics of the patients enrolled in the study are enlisted in Table 1. Average syntax score was $15.04 \pm 7.18$, all lesions were de novo, and 27 patients (67.5\%) had a type 1,1,1 Medina lesion. Twenty-three lesions (57.5\%) involved the proximal left anterior-descending artery/first diagonal branch. Only $32.5 \%$ of patients underwent an intravascular imagingguided angioplasty. Average lesion length was $21.4 \mathrm{~mm}$ in the main vessel and $11.5 \mathrm{~mm}$ in the SB. MV was always predilated and BVS received a postdilation in $100 \%$ of the cases. In $42.5 \%$ of the cases, the DCB was used during final kissing balloon inflation, and in no cases, a stent/BVS was required in the SB. Procedural success was achieved in $100 \%$ of the cases. The procedural characteristics are enlisted in Table 2. After an average follow-up of 15.5 ( \pm $11.5)$ months, we observed no MACE with only one case of target vessel revascularization $(2.5 \%)$ as shown in Table 3. All the DCBs used eluted paclitaxel (Fig. 1).

\section{Discussion}

The BVS was expected to represent fourth revolution in interventional cardiology as it offers a new technology

Table 1 Demographic and clinical characteristics of the study group

\begin{tabular}{ll}
\hline Criterion & BVS \& DCB group $(n=40)$ \\
\hline Males & $34(85 \%)$ \\
Mean age & $56.9 \pm 10.3$ \\
Hypertension & $23(57.5 \%)$ \\
DM & $9(22.5 \%)$ \\
IDDM & $5(12.5 \%)$ \\
Smoking & $14(35 \%)$ \\
Dyslipidemia & $22(55 \%)$ \\
CABG & $1(2.5 \%)$ \\
Prior PCl & $11(27.5 \%)$ \\
Stroke & $0 \%$ \\
Previous Ml & $7(17.5 \%)$ \\
Creatinine & $0.92 \pm 0.16 \mathrm{mg} / \mathrm{dl}$ \\
HB & $13.3 \pm 1.13 \mathrm{md} / \mathrm{dl}$ \\
Weight & $79 \pm 12 \mathrm{~kg}$ \\
Height & $170.9 \pm 6.1 \mathrm{~cm}$ \\
Ejection fraction & $56.6 \pm 5.1$ \\
Clinical indication & \\
Stable angina & $20(50 \%)$ \\
Unstable angina & $6(15 \%)$ \\
NSTEMl & $8(20 \%)$ \\
STEMl & $6(15 \%)$ \\
\hline
\end{tabular}


Table 2 Procedural details

\begin{tabular}{|c|c|}
\hline Procedural details & BVS \& DCB group $(n=40)$ \\
\hline \multicolumn{2}{|l|}{ Access site } \\
\hline Radial & $32(80 \%)$ \\
\hline Femoral & $8(20 \%)$ \\
\hline LM diseased & $1(2.5 \%)$ \\
\hline LAD diseased & $23(57.5 \%)$ \\
\hline LCX diseased & $11(27.5 \%)$ \\
\hline RCA diseased & $8(20 \%)$ \\
\hline Syntax score & $15.04 \pm 7.18$ \\
\hline \multicolumn{2}{|l|}{ Medina class } \\
\hline $1,1,1$ & $27(67.5 \%)$ \\
\hline $1,1,0$ & $0(0 \%)$ \\
\hline $1,0,1$ & $0 \%$ \\
\hline $0,1,1$ & $9(22.5 \%)$ \\
\hline $0,1,0$ & $1(2.5 \%)$ \\
\hline $1,0,0$ & $1(2.5 \%)$ \\
\hline $0,1,1$ & $2(5 \%)$ \\
\hline $\mathrm{OCT}$ & $3(7.5 \%)$ \\
\hline IVUS & $10(25 \%)$ \\
\hline \multicolumn{2}{|l|}{ ACC/AHA } \\
\hline A & $0 \%$ \\
\hline B1 & $2(5 \%)$ \\
\hline B2 & $34(85 \%)$ \\
\hline$C$ & $4(10 \%)$ \\
\hline Denovo lesions & $100 \%$ \\
\hline ISR & $0 \%$ \\
\hline Thrombus & $5(2.5 \%)$ \\
\hline CTO & $6(15 \%)$ \\
\hline RVD (proximal MV) (mm) & $3.13 \pm 0.4$ \\
\hline Lesion length (MV) (mm) & $21.42 \pm 16.25$ \\
\hline RVD SB (mm) & $2.31 \pm 0.34$ \\
\hline MLD MV (mm) & $0.51 \pm 0.37$ \\
\hline MLD SB (mm) & $0.77 \pm 0.62$ \\
\hline Lesion length (SB) (mm) & $11.49 \pm 6.35$ \\
\hline$\%$ stenosis MV & $83.2 \pm 13.4 \%$ \\
\hline \% stenosis SB & $66.79 \pm 24 \%$ \\
\hline Predilatation MV & $40(100 \%)$ \\
\hline Predilatation MV balloon diameter & $2.81 \pm 0.45 \mathrm{~m}$ \\
\hline Predilatation pressure (atm) & $13 \pm 0.36$ \\
\hline Scoring balloon MV & $1(2.5 \%)$ \\
\hline Rotablator MV & $0 \%$ \\
\hline Type of BVS & Absorb (100\%) \\
\hline Length BVS (mm) & $22.02 \pm 6.07$ \\
\hline Second BVS used & $7(17.5 \%)$ \\
\hline Inflation pressure BVS (atm) & $10.92 \pm 1.4 \mathrm{~atm}$ \\
\hline
\end{tabular}


Table 2 Procedural details (Continued)

\begin{tabular}{|c|c|}
\hline Procedural details & BVS \& DCB group $(n=40)$ \\
\hline Post dilatation of BVS & $40(100 \%)$ \\
\hline Post dilatation balloon diameter (mm) & $3.31 \pm 0.39$ \\
\hline Inflation pressure of postdilatation balloon (atm) & $20.3 \pm 4.4$ \\
\hline Predilatation SB & $32(80 \%)$ \\
\hline KB before stent implantation & $5(12.5 \%)$ \\
\hline Kissing balloon inflation & $23(57.5 \%)$ \\
\hline Predilatation of SB balloon diameter & $2.25 \pm 0.33$ \\
\hline Predilatation SB balloon inflation pressure & $11 \pm 3 \mathrm{~atm}$ \\
\hline \multicolumn{2}{|l|}{ Type of DCB used } \\
\hline Pantera Lux & $6(15 \%)$ \\
\hline Elutax SV & $11(27.5 \%)$ \\
\hline Restore & $6(15 \%)$ \\
\hline Sequent please & $4(10 \%)$ \\
\hline In.Pact Falcon & $10(25 \%)$ \\
\hline Danubu & $1(2.5 \%)$ \\
\hline Agent & $1(2.5 \%)$ \\
\hline Magic & $1(2.5 \%)$ \\
\hline Diameter of DCB & $2.43 \pm 0.37 \mathrm{~mm}$ \\
\hline DCB length & $20.36 \pm 6.42 \mathrm{~mm}$ \\
\hline DCB inflation pressure & $9.4 \pm 1.9 \mathrm{~atm}$ \\
\hline DCB inflation duration & $52 \pm 10 \mathrm{sec}$ \\
\hline FKB with normal balloons & $6(15 \%)$ \\
\hline FKB with DCB & $17(42.5 \%)$ \\
\hline Dissection left after DCB & $6(15 \%)$ \\
\hline \multicolumn{2}{|l|}{ Type of dissections } \\
\hline A & $5(12.5 \%)$ \\
\hline C & $1(2.5 \%)$ \\
\hline Stenting of SB & $0 \%$ \\
\hline Final \% diameter stenosis MB & $5.3 \pm 8 \%$ \\
\hline Final \% diameter stenosis SB & $13.0 \pm 16.4 \%$ \\
\hline Final MLD MB (mm) & $3.0 \pm 0.43 \mathrm{~mm}$ \\
\hline Final MLD SB (mm) & $1.9 \pm 0.5 \mathrm{~mm}$ \\
\hline Total amount of contrast (ml) & $212 \pm 117$ \\
\hline Procedural time (min) & $71.8 \pm 38 \min$ \\
\hline Total fluoroscopy time (min) & $12 \pm 3.9 \mathrm{~min}$ \\
\hline BVS/DES-related complications & $0 \%$ \\
\hline BVS underexpansion & $0 \%$ \\
\hline Longitudinal deformation & $0 \%$ \\
\hline BVS recoil & $0 \%$ \\
\hline Final TIMI less than 3 & $0 \%$ \\
\hline Intraprocedural occlusiom & $0 \%$ \\
\hline Intraprocedural death & $0 \%$ \\
\hline Peri-procedural MI & $0 \%$ \\
\hline Medications at discharge & \\
\hline
\end{tabular}


Table 2 Procedural details (Continued)

\begin{tabular}{lc}
\hline Procedural details & BVS \& DCB group $(n=40)$ \\
\hline Aspirin & $40(100 \%)$ \\
Clopidogrel & $11(27.5 \%)$ \\
Prasugrel & $4(10 \%)$ \\
Ticagrelor & $25(62.5 \%)$ \\
\hline
\end{tabular}

by transient scaffolding the vessel and eluting an antiproliferative drug [13].

Cohort B study, which tested the second generation of BVS, showed a MACE rate of 9.0\% [17]. The follow-up after 3 years in ABSORB II revealed a higher rate of target lesion failure (TLF) in the BVS group (7\%) [6].

A safety alert was issued after Food and Drug Administration (FDA) reviewed the 2-year data from the $\mathrm{AB}$ SORB III trial showing a rate of $11 \%$ in major cardiac events in patients treated with BVS in comparison to a rate of $7.9 \%$ in patients treated with Everolimus eluting stent (EES) [16].

Thrombosis was the key limitation of the BVS. This was very evident in the Absorb II trial. Specifically, 6 events occurred beyond the first year. The analysis of the 6 cases showed that the main reasons of such events were very late scaffold thrombosis and undersized scaffolds [3].

Amsterdam Investigator-Initiated Absorb Strategy AllComers Trial (AIDA) found that there was no significant

Table 3 Follow-up

\begin{tabular}{|c|c|}
\hline Follow-up & $n=40$ \\
\hline Angiographic follow-up & $13(32.5 \%)$ \\
\hline \multicolumn{2}{|l|}{ Angiographic follow-up indication } \\
\hline Stable angina & $8(9 \%)$ \\
\hline Unstable angina & $3(7.5 \%)$ \\
\hline STEMI & $1(2.5 \%)$ \\
\hline NSTEMI & $1(2.5 \%)$ \\
\hline$\%$ diameter stenosis of MV in case of angio follow-up & $2.9 \pm 3.4 \%$ \\
\hline$\%$ diameter stenosis of SB & $11 \pm 29.49 \%$ \\
\hline Average duration from index procedure to the last follow-up (days) & $444 \pm 303$ \\
\hline Binary restenosis MV & $0 \%$ \\
\hline Binary restenosis SB & $1(2.5 \%)$ \\
\hline MV MLD & $3.2 \pm 0.47 \mathrm{~mm}$ \\
\hline SB MLD & $1.784 \pm 0.6 \mathrm{~mm}$ \\
\hline MV TLR & $0 \%$ \\
\hline SB TLR & $0 \%$ \\
\hline Aspirin at follow-up & $40(100 \%)$ \\
\hline P2Y12 inhibitors at follow-up & 25 (62.5\%) \\
\hline Death & $0 \%$ \\
\hline CV death & $0 \%$ \\
\hline Non CV death & $0 \%$ \\
\hline TV Ml & $1(2.5 \%)$ \\
\hline TV MI management & POBA \\
\hline TLR & $0 \%$ \\
\hline TVR & $1(2.5 \%)$ \\
\hline Date of TVR & $10-4-2014$ \\
\hline TLR or TVR management & POBA \\
\hline $\mathrm{TL}$ thrombosis & $0 \%$ \\
\hline
\end{tabular}




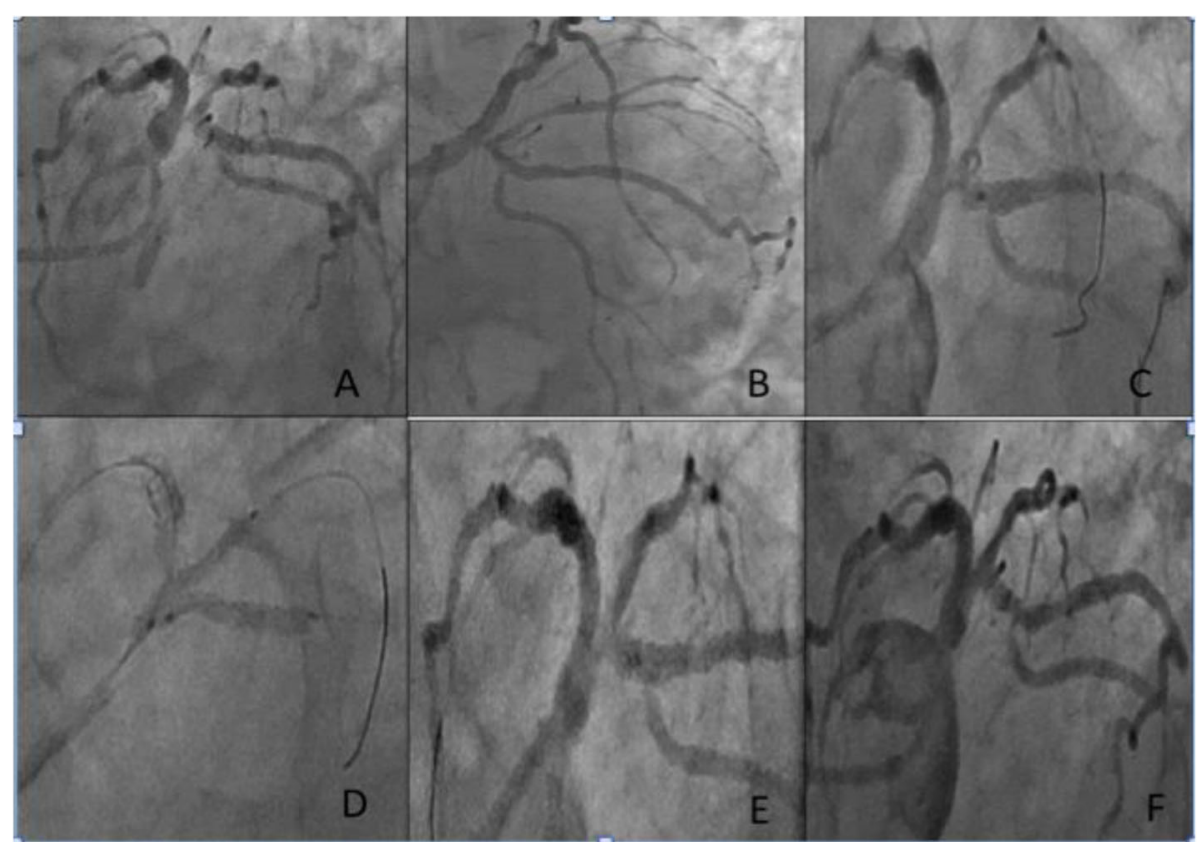

Fig. 1 a, b Bifurcation lesion involving the ostia of the LCX and RI. c After deployment of the BVS. $\mathbf{d}$ Kissing balloon inflation with DCB. e Final result at the index procedure. $\mathbf{f}$ At follow-up after 25 months

difference in the rate of target-vessel failure (TVF) between the BVS group and the stent group. There was a higher incidence of device thrombosis with BVS throughout the 2-year follow-up period [20].

Optimal management for BVS failure is still a topic for research. Different coronary devices were used to address this issue. Restenosis was successfully managed by percutaneous balloon angioplasty (POBA) and DCB [11] $[7,9]$.

The FDA recommended the PSP technique for BVS implantation. This technique includes 3 steps: the first step is the lesion preparation with a 1:1 balloon-toartery ratio using a non-compliant balloon. The second step is the appropriate sizing of the vessel with liberal use of intravascular imaging or quantitative coronary angiography (QCA). The third step is the postdilatation to high pressure using a non-compliant balloon up to $0.5 \mathrm{~mm}$ above nominal scaffold diameter. The operators were also advised to use the BVS in vessels with a reference diameter of $\geq 2.5 \mathrm{~mm}$ and $\leq 3.75$ [18].

There are a number of advantages in DCBs make them of great use in SB management in the setting of bifurcation PCI. First, the homogeneous administration of the drug; second, high concentrations of drug are delivered into the vessel wall at the moment of injury; third, original anatomy of the carina is respected [2].

Early experiences have shown how leaving a dissection after plain old balloon angioplasty was associated with increased rates of thrombotic events, early reocclusion, and recurrence of restenosis, and this was one of the main indications for the use of stents in an earlier era. Paclitaxel, when correctly delivered to the vessel wall, may have a role in facilitating the healing of coronary vessels. If the dissection is of low-medium grade, it seems safe to leave it untreated. In fact, data from the literature show how any stent strategy associated with DCB use is unsafe or yields unsatisfactory results. In a consecutive series of patients treated with newgeneration DCB for native coronary artery disease and with a final non-flow-limiting dissection, these lesions tended to heal despite their initial severity. After DCB angioplasty, a strategy of bailout stenting should be reserved to more severe, flow-limiting dissections, and in our study, all the dissections were non-flow-limiting, so no DES were needed [5].

\section{In the time-varying outcomes with the absorb} bioresorbable vascular scaffold during a 5-year follow-up: a systematic meta-analysis and individual patient data pooled study

Target lesion failure occurred in $11.6 \%$ of BVS-treated patients vs $7.9 \%$ of EES-treated patients between 0 and 3 years (HR, 1.42; 95\% CI, 1.12-1.80), and 4.3\% of BVStreated patients vs $4.5 \%$ of EES-treated patients between 3 and 5 years (HR, 0.92; 95\% CI, 0.64-1.31) ( $P$ for interaction $=.046)$. Device thrombosis occurred in $2.4 \%$ of BVS-treated patients vs $0.6 \%$ of EES-treated patients between 0 and 3 years (HR, 3.86; 95\% CI, 1.75-8.50) and $0.1 \%$ of BVS-treated patients vs $0.3 \%$ of EES-treated patients between 3 and 5 years (HR, 0.44; 95\% CI, $0.07-$ 
2.70) $(P$ for interaction $=.03$ ). This study shows that despite the worse performance of the BVS as regards TLR and scaffold thrombosis over $0-3$ years, their performance was non-inferior to DES or even better as regards TLR and thrombosis over $3-5$ years. This gives a hope for the return of the BVS to routine clinical practice after overcoming the technical and procedural issues that influence its safety and efficacy [19].

The idea of "leaving nothing behind" after PCI is a very exciting concept in modern interventional cardiology especially in bifurcation lesions. This dream started to come true with the introduction of BVS and DCB to the field of interventional cardiology which are still understudied and they open the door for further research in these technologies.

\section{Conclusion}

Our knowledge about the BVS and DCB technology is still growing. However, as it occurred with the first generation of DES, we are still learning how to appropriately use the BVS.

Management of coronary bifurcation lesions with the use of newer technologies including BVS and DCB was found to be feasible and effective at mid-term and longterm clinical follow-up with the implementation of proper implantation techniques.

\begin{abstract}
Abbreviations
BVS: Bioresorbable vascular scaffolds; CABG: Coronary artery bypass graft; CAD: Coronary artery disease; CTO: Chronic total occlusion; DCB: Drugcoated balloons; DES: Drug eluting stents; EES: Everolimus eluting stents; ISR: In-stent restenosis; KB: Kissing balloons; MACE: Major adverse cardiovascular events; MB: Main branch; MI: Myocardial infarction; MI: Myocardial infarction; MLD: Minimal lumen diameter; NSTEMI: Non-ST segment elevation myocardial infarction; PCl: Percutaneous coronary intervention; POBA: Percutaneous balloon angioplasty; QCA: Quantitative coronary angiography; RVD: Residual vessel diameter; SB: Side branch; STEMI: ST segment elevation myocardial infarction; TIMI: Thrombolysis in myocardial infarction; TLR: Target lesion revascularization; TVR: Target vessel revascularization
\end{abstract}

\section{Acknowledgements}

Not applicable.

\section{Authors' contributions}

$B C, A L, L T, A l, D P, S G, T E$, and $A Z$ were the operators and collected the data. $M E$ analyzed the data, wrote the manuscript, and is the corresponding author. BC, TE, and AZ analyzed the data and revised the manuscript. All authors have read and approved the manuscript.

\section{Funding}

The authors did not receive any funds.

\section{Availability of data and materials}

The datasets used and/or analyzed during the current study are available from the corresponding author on reasonable request.

\section{Ethics approval and consent to participate}

Ethics approval was granted form the ethics committee of Alexnadria Univeristy, serial number: 020914, IRB no: 00012098. As this was a retrospective study, consent to participate was not required.
Consent for publication

Not applicable.

\section{Competing interests}

The authors declare that they have no competing interests.

\section{Author details}

${ }^{1}$ Interventional Cardiology, San Carlo Clinic, Milano, Italy. ${ }^{2}$ Faculty of Medicine, University of Alexandria, Alexandria, Egypt. ${ }^{3}$ Montefiori Medical Center, New York, USA. ${ }^{4}$ San Donato Clinic, Milano, Italy. ${ }^{5}$ Sant'Ambrogio Clinic, Milano, Italy. ${ }^{6}$ Policlinico Giaccone, Palermo, Italy. ${ }^{7}$ Ospedale di Agrigento, Agrigento, Italy. ${ }^{8}$ Fondazione G. Monasterio CNR-Regione Toscana, Pisa, Massa, Italy

Received: 19 September 2019 Accepted: 19 November 2019

Published online: 16 December 2019

\section{References}

1. Banning AP, Lassen JF, Burzotta F et al (2019) Percutaneous coronary intervention for obstructive bifurcation lesions: the 14th consensus document from the European Bifurcation Club. Eurolntervention 15:90-98. https://doi.org/10.4244/ElJ-D-19-00144

2. Belkacemi A, Agostoni P, Voskuil M, Stella PR (2011) Coronary bifurcation lesions treated with the drug-eluting balloon: a preliminary insight from the DEBIUT study. Eurolntervention 7 Suppl K:K66-9. https://doi.org/10.4244/ EIJV7SKA12

3. Chevalier B, Onuma Y, van Boven A et al (2016) Randomised comparison of a bioresorbable everolimus-eluting scaffold with a metallic everolimus-eluting stent for ischaemic heart disease caused by de novo native coronary artery lesions: the 2-year clinical outcomes of the ABSORB II trial. Eurolntervention 12:1102-1107. https://doi.org/10. 4244/EIJY16M08_01

4. Colombo A, Moses JW, Morice MC et al (2004) Randomized study to evaluate sirolimus-eluting stents implanted at coronary bifurcation lesions. Circulation 109:1244-1249. https://doi.org/10.1161/01.CIR. $0000118474.71662 . \mathrm{E3}$

5. Cortese B, Silva Orrego P, Agostoni P et al (2015) Effect of drug-coated balloons in native coronary artery disease left with a dissection. JACC: Cardiovascular Interventions 8:2003-2009. https://doi.org/10.1016/j.jcin. 2015.08.029

6. Diletti R, Serruys PW, Farooq V et al (2012) ABSORB II randomized controlled trial: a clinical evaluation to compare the safety, efficacy, and performance of the Absorb everolimus-eluting bioresorbable vascular scaffold system against the XIENCE everolimus-eluting coronary stent system in the treatment of subjects with ischemic heart disease caused by de novo native coronary artery lesions: rationale and study design. Am Heart J 164:654-663

7. Elwany M, Latini RA, Di Palma G et al (2017) First experience of drug-coated balloons for treatment of bioresorbable vascular scaffold restenosis, Cardiovasc Revasc Med. https://doi.org/10.1016/j.carrev.2017.03.020

8. Kraak RP, Tijssen RYG, van Dongen IM et al (2019) Bioresorbable vascular scaffold versus Xience metallic stents: outcomes in the AIDA trial stratified by SYNTAX score. Eurolntervention. https://doi.org/10.4244/EIJ-D-18-00884

9. Latini RA, Buccheri D, Cortese B (2017) First reported use of drug-coated balloon for bioresorbable in-scaffold restenosis. Cathet Cardiovasc Interventions 89:676-678. https://doi.org/10.1002/ccd.26803

10. Loh JP, Waksman R (2012) Paclitaxel drug-coated balloons: a review of current status and emerging applications in native coronary artery de novo lesions. JACC: Cardiovasc Interv 5:1001-1012. https://doi.org/10. 1016/j.jcin.2012.08.005

11. Longo G, Granata F, Capodanno D et al (2015) Anatomical features and management of bioresorbable vascular scaffolds failure: a case series from the GHOST registry. Catheterization and Cardiovascular Interventions 85: 1150-1161. https://doi.org/10.1002/ccd.25819

12. Medina A, Suárez de Lezo J, Pan M (2006) A new classification of coronary bifurcation lesions. Rev Esp Cardiol 59:183

13. Onuma Y, Serruys PW (2011) Bioresorbable scaffold. Circulation 123:779-797. https://doi.org/10.1161/CIRCULATIONAHA.110.971606

14. Otsuka F, Pacheco E, Perkins LEL et al (2014) Long-term safety of an everolimus-eluting bioresorbable vascular scaffold and the cobalt-chromium XIENCE V stent in a porcine coronary artery model. Circ Cardiovasc Interv 7: 330-342. https://doi.org/10.1161/CIRCINTERVENTIONS.113.000990 
15. Sanchez OD, Yahagi K, Byrne RA et al (2015) Pathological aspects of bioresorbable stent implantation. Eurolntervention 11 Suppl V:V159-65. https://doi.org/10.4244/EIJV11SVA39

16. Serruys PW, Chevalier B, Dudek D et al (2015) A bioresorbable everolimuseluting scaffold versus a metallic everolimus-eluting stent for ischaemic heart disease caused by de-novo native coronary artery lesions (ABSORB II): an interim 1-year analysis of clinical and procedural secondary outcomes from a randomised controlled trial. Lancet 385:43-54. https://doi.org/10. 1016/S0140-6736(14)61455-0

17. Serruys PW, Onuma Y, Garcia-Garcia HM et al (2014) Dynamics of vessel wall changes following the implantation of the absorb everolimus-eluting bioresorbable vascular scaffold: a multi-imaging modality study at 6, 12, 24 and 36 months. Eurolntervention 9:1271-1284. https://doi.org/10.4244/ EIJV9111A217

18. Steinvil A, Rogers T, Torguson R, Waksman R (2016) Overview of the 2016 U.S. Food and Drug Administration Circulatory System Devices Advisory Panel Meeting on the Absorb Bioresorbable Vascular Scaffold System. JACC: Cardiovascular Interventions 9:1757-1764. https://doi.org/ 10.1016/.j.jin.2016.06.027

19. Stone GW, Kimura T, Gao R et al (2019) Time-varying outcomes with the absorb bioresorbable vascular scaffold during 5-year follow-up: a systematic meta-analysis and individual patient data pooled study. JAMA Cardiol. https://doi.org/10.1001/jamacardio.2019.4101

20. Wykrzykowska JJ, Kraak RP, Hofma SH, et al (2017) Bioresorbable scaffolds versus metallic stents in routine PCl. http://dxdoiorg/101056/ NEJMoa1614954 NEJMoa1614954. doi: https://doi.org/10.1056/ NEJMoa1614954

\section{Publisher's Note}

Springer Nature remains neutral with regard to jurisdictional claims in published maps and institutional affiliations.

\section{Submit your manuscript to a SpringerOpen ${ }^{\circ}$ journal and benefit from:}

- Convenient online submission

- Rigorous peer review

- Open access: articles freely available online

- High visibility within the field

- Retaining the copyright to your article

Submit your next manuscript at $\boldsymbol{\nabla}$ springeropen.com 